\title{
Discovery of Reduction in Photosynthesis Correlation to Carbon Dioxide Increase
}

\author{
Dave White $\mathrm{CH} \mathrm{E}$
}

\begin{abstract}
Since 1950 the Amazon Rain-forest has been deforested. An average of 12 million hectare per year. This deforestation causes a minimum of $30 \%$ of the biomass to be burned. The burning of the biomass is adding billion of tons of carbon dioxide to the atmosphere. The carbon dioxide has overwhelmed the rain-forest and caused massive decay. The rain-forest has now become and oxygen sink and carbon dioxide producer. To solve these issues the deforestation and burning needs to stop. Then after 10 years the burning can continue $10 \%$ a year for 10 years. This will heal the amazon and bring down atmospheric carbon dioxide. After a few years the global carbon dioxide will start to decrease. After 10 years the rain-forest will be healed. However minus 860 million hectares. In addition if we plant trees and shrubs worldwide we will bring down the atmospheric carbon dioxide much faster.
\end{abstract}

Index Terms - Carbon dioxide increase, carbon dioxide scavenging, Climate Change, rain-forest.

\section{DATA}

For the past few decades Carbon dioxide emissions have been shown to be the cause for atmospheric carbon dioxide concentration increase. Many papers have been written about the correlation shown in Graph 1 below. This was the only accepted correlation available and it has been used extensively in papers shown at conferences and published in journals. Papers have also shown the oceans to be a sink for carbon dioxide. The other sources of sinks for carbon dioxide are the rain forests and other plants for carbon dioxide scavenging. I look at the carbon dioxide issue as a production issue. The producers are the carbon dioxide emissions and the consumers are the plants and diffusion. We have effectively reduced the emissions at the same time we have crippled the consumption. One hectare of rainforest removes up to 105 tons of carbon dioxide [1]. We have transformed 860 million hectares so far with over 12.3 million hectares per each year on average. At 410ppm we have 3501 moles of carbon dioxide in the troposphere. This is 0.154 metric tons. This could all be consumed if we added hectares to the rainforest instead of subtracting. The older trees and shrubs are dying off because they are over worked with the increase in carbon dioxide from local burning [2].

This massive decay has caused the rainforest to change to an oxygen sink to take care of all the decay. EPA: "Carbon dioxide enters the atmosphere through burning fossil fuels (coal, natural gas, and oil), solid waste, trees and wood products, and because of certain chemical reactions (e.g.,

Manuscript received December 1, 2017; revised February 27, 2018.

The author is with Climate Change Truth Inc., USA (e-mail: truth@cctruth.org). manufacture of cement). Carbon dioxide is removed from the atmosphere (or "sequestered") when it is absorbed by plants as part of the biological carbon cycle [3]." Currently the global carbon dioxide emissions are decreasing. Graph 3 shows this. I cannot find any published plausible reason why the carbon dioxide concentration in the atmosphere is still increasing while the emissions are decreasing.

In late spring, early summer 2017, I was looking at how the carbon emissions were decreasing with all the money spent on it [4]. Fig. 3 shows the decreasing carbon dioxide emissions. Then the news came out the carbon dioxide concentration changed from $405 \mathrm{ppm}$ to $410 \mathrm{ppm}$ at the Mauna Loa Observatory [5].

I then looked at many other causes of carbon dioxide increase and found the best one is the destruction of the rain forest. I cound not find any other reports on the destruction of the rain forest to carbon dioxide increase except in the carbon dioxide emission calculations[6]. Carbon dioxide concentrations involve considerably more than fossil fuel emissions, which is what is generally reported. Changes in forest cover and other land uses also play a role. It's a very dynamic system, and the year-to-year change depends upon temperatures, ocean and atmospheric transport, and the amount and location of emissions. So, one would not expect the atmospheric concentrations to change in exact proportion to changes in industrial emissions. The Rain-forest deforestation started in 1950 and continues today.

$$
r_{x y}=\frac{\sum_{i=1}^{n}\left(x_{i}-\bar{x}\right)\left(y_{i}-\bar{y}\right)}{\sqrt{\sum_{i=1}^{n}\left(x_{i}-\bar{x}\right)^{2} \sum_{i=1}^{n}\left(y_{i}-\bar{y}\right)^{2}}}
$$

Fig. 1. Pearsons regression formula.

Greenhouse gases like all gases diffuse until they are equi-distant to each other at the pressure and temperature they are at. At STP (Standard Temperature and Pressure, 25C, 1 Atmosphere), Carbon dioxide in air has a diffusion coefficient of $16 \mathrm{~mm} 2 / \mathrm{s}$, and in water its diffusion coefficient is $0.0016 \mathrm{~mm} 2 / \mathrm{s}$. It is 10000 times more likely to diffuse in Air than ocean [7] This NASA paper describes the ocean interaction and states for molecular diffusion the concentration in the ocean is 50 times more than the atmosphere concentration. It does not mention ocean spray as any source. The driving force for diffusion is much greater in the direction of the exosphere where the concentration is 
around $25 \mathrm{ppm}$. The only carbon dioxide that goes into the ocean is from ocean spray. This is the same principle we chemical engineers use when designing an Industrial exhaust scrubber. Over half of the ocean's surface is at STP at any time. carbon dioxide does not freeze in the upper atmosphere either. The freezing point in the mesosphere at .14 ATM (Atmosphere) pressure is $-100 \mathrm{C}$ and the temperature in the mesosphere is $-90 \mathrm{C}$. The residence time of carbon dioxide in the atmosphere used to be 5 to 50 years. Currently it is estimated at 500-2000 years. [8]. Carbon Dioxide just sits in the atmosphere diffusing from the surface to the exosphere, being carried by atmospheric winds and waiting to be scavenged. With less photosynthesis it is easy to see why the carbon dioxide level is increasing. The more alarming issue is the loss of oxygen production. The oceans provide some oxygen to the air from plants living on the surface. The concentration of oxygen in the ocean is much less than the concentration in the troposphere so it does not diffuse out of the ocean itself. Photosynthesis is a process by which a plant takes in carbon dioxide and makes more plant with the Carbon. Then exhales the $\mathrm{O}_{2}$ for us to breathe. This process is called oxygenic photosynthesis. carbon dioxide $+2 \mathrm{H}_{2} \mathrm{O}+$ photons $\rightarrow\left[\mathrm{CH}_{2} \mathrm{O}\right]+\mathrm{O}_{2}+\mathrm{H}_{2} \mathrm{O}$. I contacted a reseacher in South America and he supplied me with the acreage numbers in this report. Figure 1 below shows the corelation coeficient calculation method I will use. This is "Pearson's Correlation". The better value is the one closest to 1.0. The data for Rain Forest devastation vs. Carbon dioxide increase from online government data as much as possible. This data supplied by the researcher at Mongabay. Mongabay has been researching rain forest loss since 1999. No other complete year by year data for rain forest devastation is available. The other data is from the well-known graph of Carbon dioxide and carbon emissions [9]. This is the best data on carbon dioxide emissions as a cause of carbon dioxide concentration increase. The raw data was used from each Graph 1 and 2.

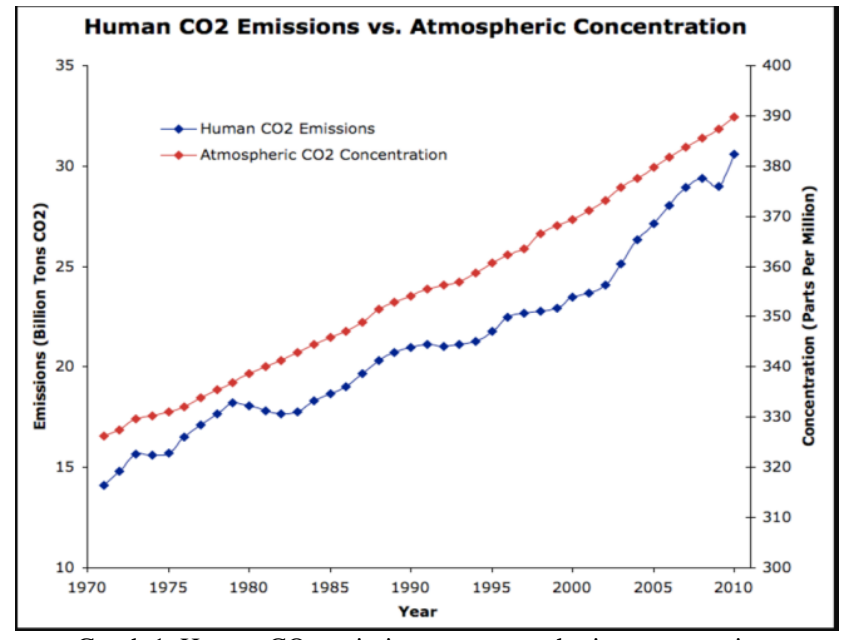

Graph 1. Human $\mathrm{CO}_{2}$ emissions vs. atmospheric concentration.

I plotted the carbon dioxide concentration and Rain Forest devastation ( $\mathrm{rf} \mathrm{dev})$ at $5 \%$-time intervals. Then calculated each part of the formula. The correlation coefficient obtained is 0.99 . The Hectare value is used because each hectare of rainforest contains the same amount of carbon dioxide scavenging plants. Then using the same method, I calculated for Carbon dioxide emissions and Carbon dioxide concentration increase. The correlation coefficient obtained is 0.72 .

The data for Graph 2 came from a scholar in South America [10].

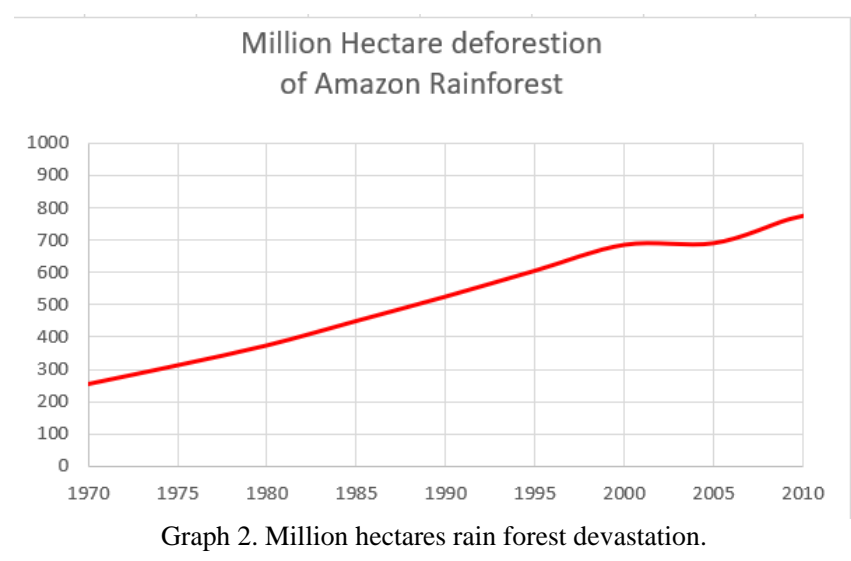

Further evidence that carbon dioxide emissions do not corelate to the current carbon dioxide increase is below. The carbon dioxide concentration is on the rise at Mauna Loa Observatory even though the carbon dioxide emissions are decreasing overall. Only China is still flat and has not decreased yet. India is increasing. The atmospheric concentration is very dynamic, and we would see a decrease in concentration if carbon emissions were the main cause of the rise since 1950. The emissions data does have a reported 3 billion tons from deforestation built in it.

1 Hectare $=2.47$ acres $=$ ha

1950-1979

Tropics: $318 \mathrm{M}$ ha

Temperate: $18 \mathrm{M}$ ha

\section{0-1995}

Tropics: $220 \mathrm{M}$ ha

Temperate: $6 \mathrm{M}$ ha

$226 \mathrm{M}$ ha total or $15.1 \mathrm{M}$ ha/year

In 2011 , tropical forest loss at $11.33 \mathrm{M}$ ha/year in the $1990 \mathrm{~s}$ and $9.34 \mathrm{M} \mathrm{ha/year}$ in the 2000s). It had global forest loss at $16 \mathrm{M} \mathrm{ha} /$ year in the $1990 \mathrm{~s}$ and $13 \mathrm{M} \mathrm{ha} /$ year in the $2000 \mathrm{~s}$.

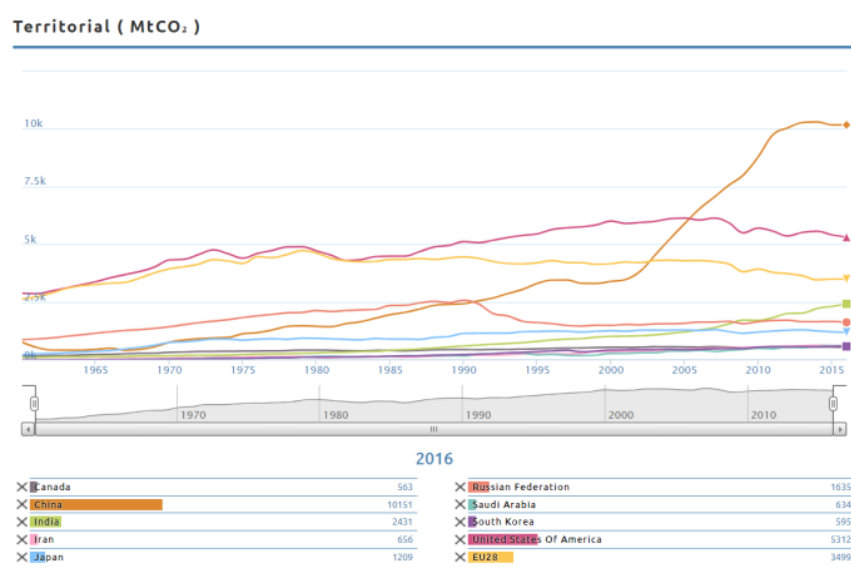

Graph 3. Worldwide global carbon dioxide emission outputs by country.

Mauna Loa data proves it's the rain forest. Graph 4 shows 
two regimes. Pre-1950 increase is one slope and post 1950 is a greater slope. Taking the pre-1950 slope to current year the value of 340ppm is seen. Then using regression, I received at 0.98 correlation. This shows the rainforest burning effect is around $60 \mathrm{ppm}$. Graph 5 from Mauna Loa data shows the carbon dioxide from whatever source is evenly distributed in the atmosphere. On average the deforestation is 12.2 million hectares with 10 million wood debris piles to burn per year.



World atmospheric carbon dioxide by latitude.

Calculating the rain-forest carbon emission.

The $\mathrm{CO}_{2}$ increase can be seen in Graph 4 from Mauna Loa with two distinct regimes. The industrial part (pre-1950) shows without the deforestation of the rainforest the current carbon dioxide concentration would be 340 to $360 \mathrm{ppm}$. The deforestation started in 1950 and shortly after that we see the current regime rise. The current regime includes carbon dioxide emissions plus rain-forest burning. If we extend the industrial line and calculate the regression we get a collation coefficient of 0.98. Without the rain forest component, we would have a ppm reading of around $360 \mathrm{ppm}$ today.

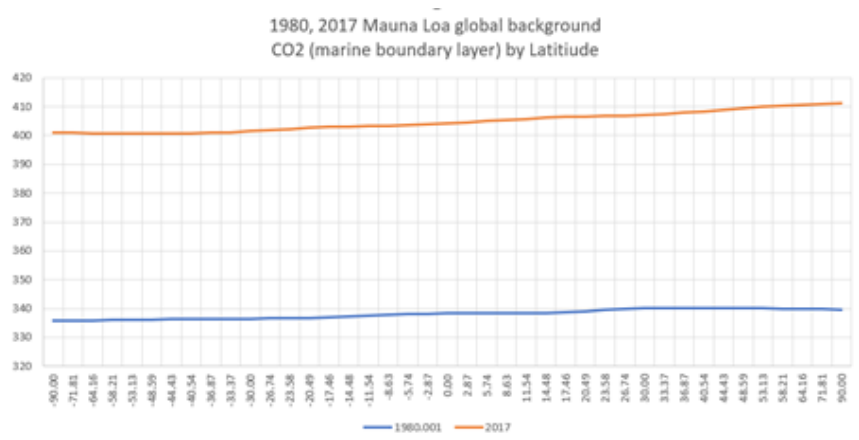

Graph 5. Atmospheric $\mathrm{CO}_{2}$ by latitude.

At 3 billion tons per year [11], the deforestation contribution of the 38 billion total is $12.6 \%$. The IPCC recognizes this impact. Anthropogenic forest degradation and biomass burning (forest fires and agricultural burning) also represent relevant contributions. Annual GHG emissions from agricultural production in 2000-2010 were estimated at 5.0-5.8 GtCO2eq/yr [11]. When we stop the deforestation, and burning, the rain forest will heal, and the concentration of carbon dioxide will decrease.

\section{CONCLUSION}

This report has shown a much stronger correlation of carbon dioxide scavenging loss to the observed increase in carbon dioxide. (0.99 vs. 0.72) As hectare upon hectare of rain forest are destroyed this increases world carbon dioxide dramatically.

This is the main reason the carbon dioxide is higher now than in 1950. We need to stop the burning and deforestation of the rainforest. Also, we need to plant native shrubs and trees all over the world.

The good news is a 30000 hectares of rain forest will be reforested by 2030 [12]. The Paris agreement with Brazil is for 12 million more Hectare's to be reforested. This is good but still not enough.

Over $\$ 2$ billion have been spent in the last ten years trying to bring down the carbon dioxide by reducing emissions. While it is good to bring down carbon emissions this alone will never work to bring down the carbon dioxide level.

Stopping the deforestation is one step. Also, the burning must stop and then after 10 years the burning start with a maximum of $10 \%$ a year.

It will take nearly 10 years to heal the rain-forest and resume 105 tons per hectare scavenging.

The second thing that needs to be done is plant 100 million native trees and shrubs all over the world. This will start to bring down the atmospheric carbon dioxide in a few years. Certainly, if the time and money was spent stopping the deforestation of the rain forest and planting native shrubs and trees the carbon dioxide level would start to retreat soon.

\section{REFERENCES}

[1] Growing air foundation. (2017). [Online]. Available: http://www.growingairfoundation.org/facts/,

[2] Science mag. (2017). [Online]. Available: http://www.sciencemag.org/news/2015/03/amazon-rainforest-ability-s oak-carbon-dioxide-falling

[3] Ghg emissions. [Online]. Available: https://www.epa.gov/ghgemissions/overview-greenhouse-gases

[4] $\mathrm{CO}_{2}$-emissions. [Online]. Available: http://globalcarbonatlas.org/en/CO2-emissions

[5] Mauna Loa Observatory. (2017). [Online]. Available: https://www.esrl.noaa.gov/gmd/obop/mlo/

[6] Scientificamerican. (2017). [Online]. Available: https://www.scientificamerican.com/article/deforestation-and-globalwarming/

[7] 1984 Welty Wicks and Wilson, Fundamentals of Momentum Heat and Mass Transfer.

[8] IPCC Working Group. (2017). [Online]. Available: https://www.ipcc.ch/ipccreports/tar/wg1/016.htm

[9] Human carbon dioxide emissions (blue, left y-axis, Source: IEA) vs. atmospheric $\mathrm{CO}_{2}$ concentration (red, right y-axis, Source: Mauna Loa record.

[10] South American researcher. [Online]. Available: https://news.mongabay.com/2011/02/forest-loss-slows-as-un-marks-in ternational-year-of-forests/

[11] IPCC. [Online]. Available: http://www.ipcc.ch/pdf/assessment-report/ar5/wg3/ipcc_wg3_ar5_cha pter11.pdf

[12] Amazon-reforestation-brazil. [Online]. Available: https://www.ecowatch.com/amazon-reforestation-brazil-2504950622. html

David (Dave) White is a chemical engineer currently working on climate change. He has 30 years' experience since graduation in 1984, promoting responsibility to environment and health of all species.

Dave White graduated in chemical engineering in 1984. During the time at Oregon State University Dave worked on a cross flow counter current scrubber for coal fired power plants. Then he moved to Hillsboro with his 
wife and worked in Semiconductors. In 2006 Dave along with Dr. Tom Wallow produced a paper on ArF double patterning for semiconductors. This multi-pattering scheme is widely used in today's semiconductor manufacturing plants. In 2011 Dave started a consulting business for
Semiconductors. In 2017 Dave Started Climate Change Truth Research Inc. Dave is seeking the truth about climate change. His research interests are evaporation from the ocean, rain forest destruction effects and diffusion of $\mathrm{CO}_{2}$ through the atmosphere. 